Article

\title{
The Evolutionary Use of Curved Wood in Korean Traditional Architecture
}

\author{
Seong Lyong Ryoo and Hyun Chul Youn* \\ Department of Architecture, Korea University, Anam-ro 145, Seoul 136-713, Korea; ryoos1@korea.ac.kr \\ * Correspondence: nadaeworld@korea.ac.kr; Tel.: +82-10-7126-1956
}

Received: 5 November 2019; Accepted: 13 November 2019; Published: 20 November 2019

\begin{abstract}
Various types of curved wooden have always been used in traditional Korean architecture. One component is a curvaceous column with varying thicknesses, and the others are curved beams or girders that are needed to support the roof and present diverse curvature. By examining the historical alteration of the parts and shapes of these curved members, it is possible to identify the sustainable aspects of Korean traditional architecture and infer the influence of the historical background on forming the sustainability of the architecture. To be specific, while the Goryeo Dynasty (10-14 C) showed an aesthetic summit of temple architecture in terms of extravagant curved wooden members precisely calculated and designed under the influence of Buddhism and aristocracy, the early Joseon Dynasty (15-16 C) presented restrained curve forms of wooden members with fewer materials and a faster process due to Neo-Confucianism, which emphasized austerity. After tremendous social crisis and two wars, the mid-Joseon Dynasty (17-18 C) showed creative indigenous houses with naturally curved timbers, minimizing the manufacturing process and maximizing the pragmatic functionality of the space under the influence of the wars and Silhak (the Realist School of Confucianism). In addition, the late Joseon Dynasty (19-20 C) presented office buildings with strengthened dynamic shapes of the naturally curved timbers as symbolic expression, which is an expanded concept beyond the functionality. In Korean traditional architecture, curved wood members have been used without interruption-although in varying degrees depending on social and economic situations-and have continued to be one of the characteristics of Korean architecture.
\end{abstract}

Keywords: curved wooden members; restrained curve forms; naturally curved timbers; functionality; symbolic expression

\section{Introduction}

Korea has a long history of wood architecture. The term 'adaptable to nature' tends to be a common modifier to express the characteristics of Korean traditional architecture [1]. For Korean cases, the concept of convergence and harmony with nature [2] has also been emphasized to describe the very nature of Korean traditional wooden buildings. It is true that Korean wood architecture has uniquely evolved, in a way adapting and revealing the materiality of wood. While they share some common features over time, the wooden structures have different ideas and styles according to the time, as shown between those of the Goryeo (10-14 C) and Joseon (15-20 C) Dynasties [3].

The differences between the times have been also manifested in paintings, crafts, and many other artworks as well. Perhaps, pottery is among the most notable examples to understand the differences. A Korean daily newspaper once ran an advertisement of an exhibition containing a picture of Goryeo celadon and Joseon white porcelain, which effectively showed the different aesthetics of the different times (Figure 1). While the Goryeo celadon shows elaborate and splendid expression in symmetrical form, the Joseon white porcelain presents simple and plain aspects with asymmetrical proportion. The 
expressional differences of form come from various factors such as religion, ideology, international relations with the adjacent countries, and collective public tastes of the time [4].

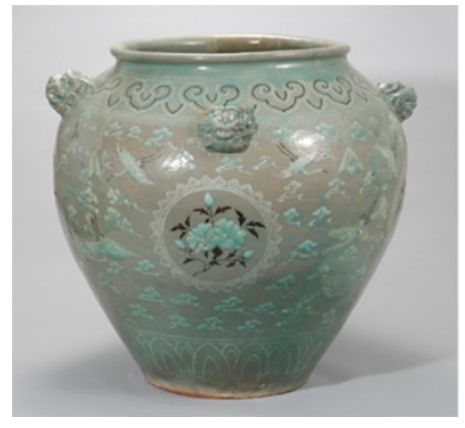

(a)

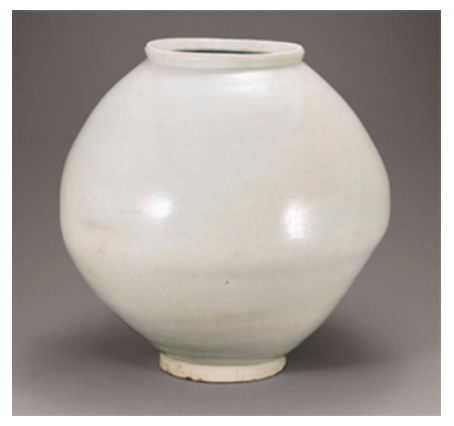

(b)

Figure 1. (a) Goryeo celadon; (b) Joseon white porcelain. (Source: DonA Ilbo Article 2019.7.1).

Similar to the craft fields, this research attempts to verify that the period of Korean traditional architecture can be divided by certain noticeable architectural elements of the buildings. In particular, the research focuses on the curve-shaped wooden members of Korean traditional architecture, which have not only universality but also diversity of the times from Goryeo to Joseon. Scrutinizing the historical alteration of the curved wooden members, this research tries to reveal that the change of the parts and shapes of the members are critical evidences of the sustainability of Korean traditional architecture reflecting the social and cultural background of the era.

\section{Materials and Methods}

\subsection{Materials}

The research subjects are chosen among the listed buildings that contain curved or bent wooden members of the framework. Especially, it is limited to the buildings of designated national cultural properties in Korea. Since they are under strict national level management, they, as objective research sources, are credible to retain their appearance at the time of construction and are recognized as a representative example of the era in historical, academic, and artistic aspects.

There are several Goryeo-era buildings that still remain in Korea, including Andong Bongjeongsa Geukrakjeon in the 10th century [5], the oldest wooden building in Korea, Yeongju Buseoksa Muryangsujeon in the 11th century [6], and Yaesan Sudeoksa Daeungjeon in 1308 [7]. Most of them are Buddhist temple buildings, which also include Yeongju Buseoksa Josadang and Yeongcheon Eunhaesa Geojoam Yeongsanjeon. If it is not a temple, the main gate of Gangneung Gaeksa is one of the Goryeo-era buildings we can still witness [8]. Compared to the Goryeo Dynasty, many more Joseon-era buildings remain. In terms of the purpose of building, for instance, many more types of Joseon's buildings have been left, including palaces, housings, educational facilities, and villas, while Goryeo's consist merely of the Buddhist temples and government buildings. Therefore, due to the large number and variety, it is relatively easy to group the buildings of Joseon Dynasty into three periods: the early, middle, and latter.

\subsection{Methods}

The research is conducted by site visit and data analysis from the collected historical records. Figure 2 shows the specific locations of the research cases with the map of South Korea. After classifying the periods of the traditional buildings, it shows that there are certain typical curved wooden members that represent a particular period. For example, Umiryang (cow-tail-shaped beam, interconnects purlins with different levels in the form of steps) was used from the Goryeo Dynasty to the early Joseon 
Dynasty, and is similar to the Baeheulim (entasis) column. Chungryang (a beam perpendicular to the girder, with one end hanging on the girder and the other side hanging on the lateral flat) is not seen in the Goryeo Dynasty, but it started to be used in the early Joseon Dynasty and was used until the late Joseon Dynasty. Thus, this research studies the detailed positions and functions of the curved wooden members. In addition, in order to analyze the formation of the members, curvature is calculated, and it was checked whether the member was made by processing or in its natural state.

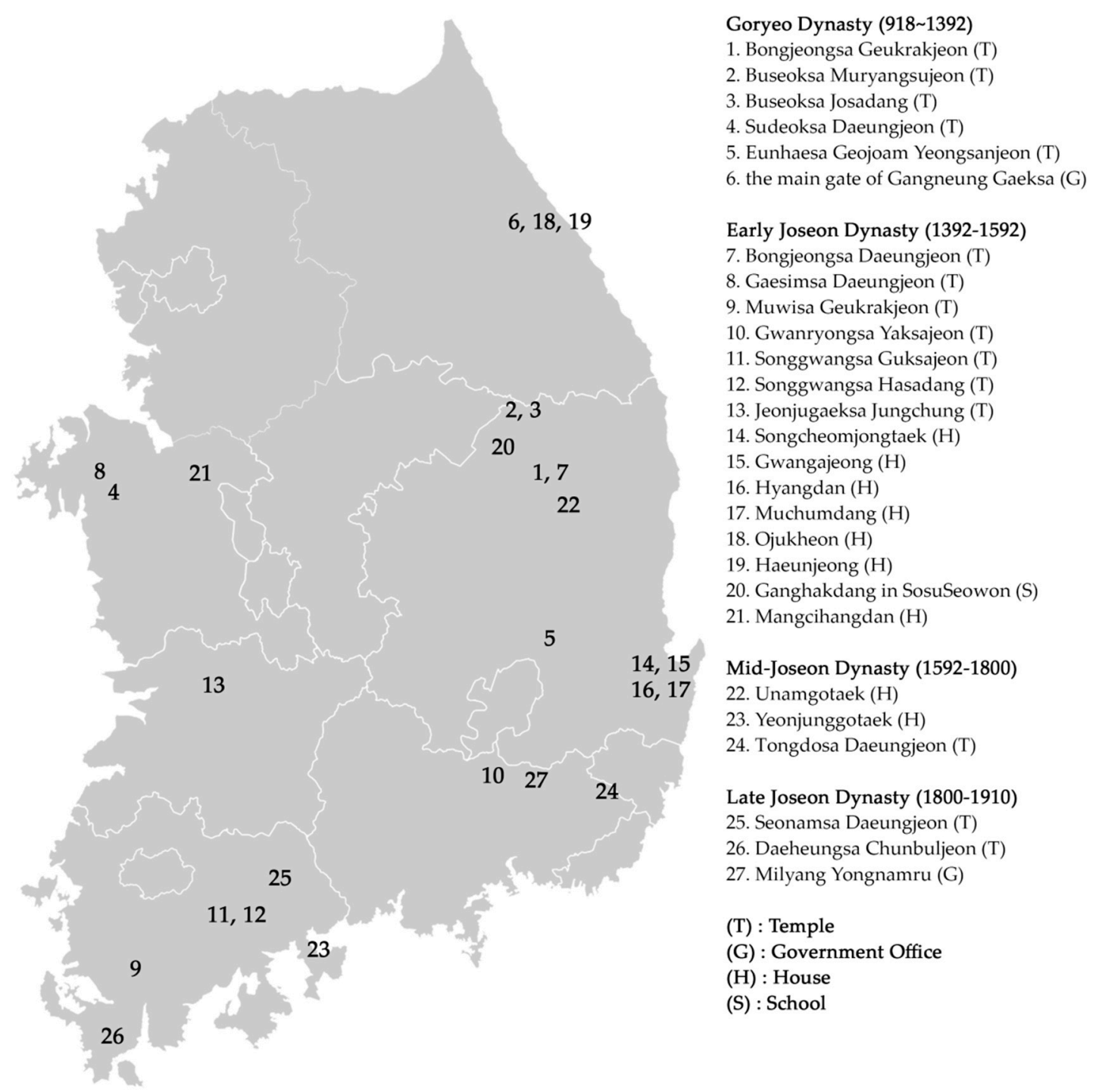

Figure 2. The key map of South Korea and the specific locations of the cases (source: author).

\section{Goryeo Dynasty (Approximately 918-1392): Curves of Delicacy and Exquisiteness}

In the Goryeo Dynasty, the cross-section of the girder is elaborately trimmed to resemble pottery (Figure 3). Cross-sections 1 to 4 were found in the buildings of the Goryeo Dynasty, Bongjeongsa Geukrakjeon, Buseoksa Muryangsujeon, Seongbulsa Geukrakjeon, and Buseoksa Josadang, respectively; and five to 10 were found from the buildings of the Joseon Dynasty. The cross-sections in the buildings of the Goryeo Dynasty look similar to pottery, having narrower tops and bottoms than the center. 


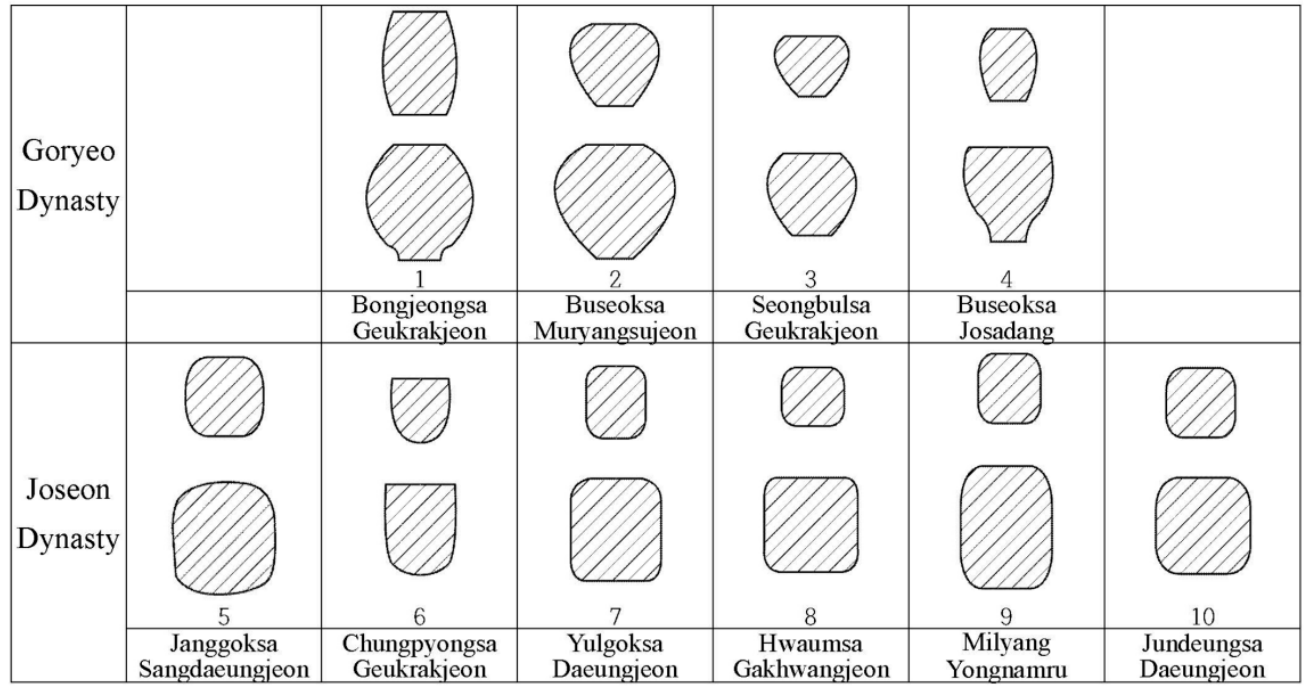

Figure 3. The Sections of cross-beams (source: author's edit [9]).

In addition, the Baeheulim-style column and Umiryang, "cow-tail-shaped" beam are among the most notable examples of Korean traditional techniques applied to curves. The Baeheulim-style column is one of the typical characteristics of wooden architecture in the Goryeo period, where a convex curve is applied to wooden building columns, which is known as the entasis. In general, the diameter of a Baeheulim column's cross-section is the widest one-third of the way from the bottom, becoming narrower at both ends [10]. Based on these dimensions, it is easy to see the deliberate design of the Baeheulim column where the diameter of the bottom part is the second widest and the top is the smallest (Figure 4a). Among the remaining wooden buildings in Korea, the building with the greatest degree of curvature in the Baeheulim column can be found at the main gate of Gangneung Gaeksa (Figure 4b). All the buildings of the Goryeo Dynasty have the Baeheulim-style columns to some degree. As seen in the wooden architecture of the Goryeo Dynasty, the Baeheulim columns were deliberately designed curves to maximize the aesthetic expression of the curved lines as well as to maintain a stable visual depth.

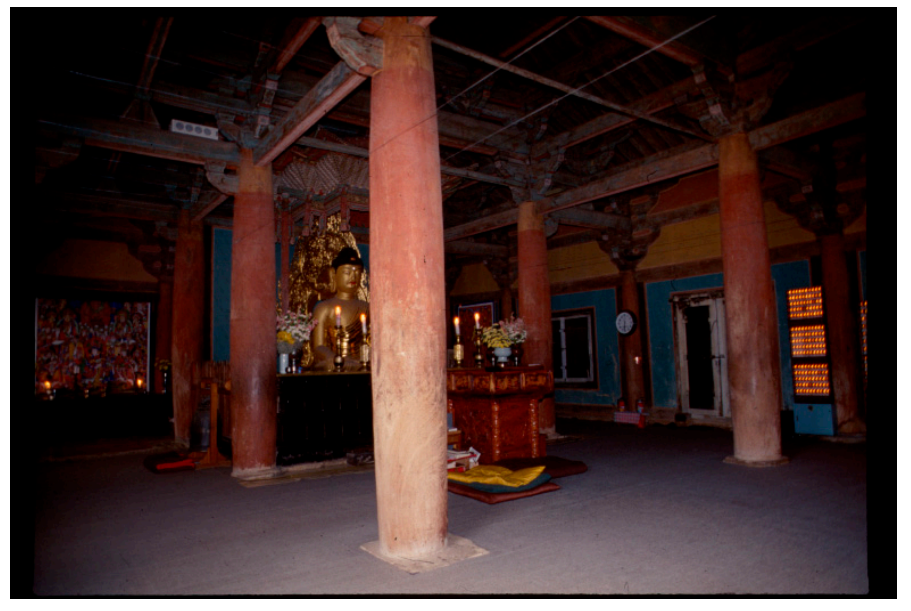

(a)

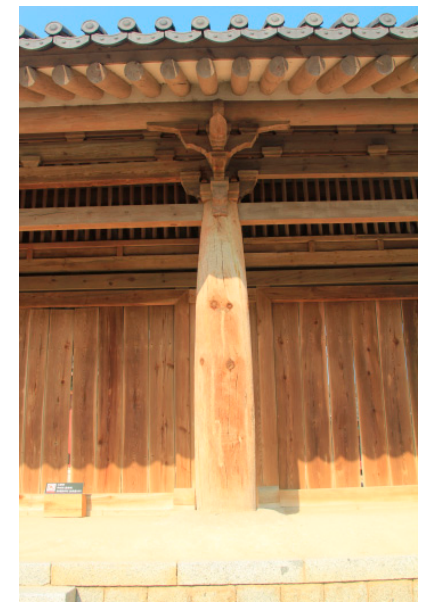

(b)

Figure 4. (a) Buseoksa Muryangsujeon Interior Column; (b) Gangneung Gaeksamun Exterior Column (source: author). 
There was a similar technique in China, which is called Suōzhù according to Yíngzàofăshì [11,12]. In addition, the corridor and main building of Horyuji in Japan, the oldest existing wooden building, was once compared to the entasis columns of Greek temple architecture. From these examples, we can assume that the technique of having entasis-like curves in building columns in that era had been widely used in the architecture of Korea, China, and Japan.

Umiryang (cow-tail-shaped beam) is another typical characteristic of wooden architecture in the Goryeo period. Built in 1308, Sudeoksa Daeungjeon is famous for the beautiful appearance of its profile (Figure 5). Its Matpae-style roof (gable roof) enables both profiles of the building to be visually exposed, and thus reveals the beauty of the curved lines of Hongyebo (rainbow-shaped beam). Connecting adjacent purlins of the roof, the three Hongyebos are installed on each side, resulting in a total of six symmetrically placed on both sides from the center of the building. Linking and fixing the members at different levels, this beam Umiryang also creates an aesthetically beautiful composition. Umiryangs are also found in the main gate of Gangneung Gaeksa. However, the differences are that there are fewer Umiryangs, and its curvature is less steep because the building size is smaller. This architectural element is important evidence for the cultural and architectural exchanges between Korea and China, especially southern China [13].

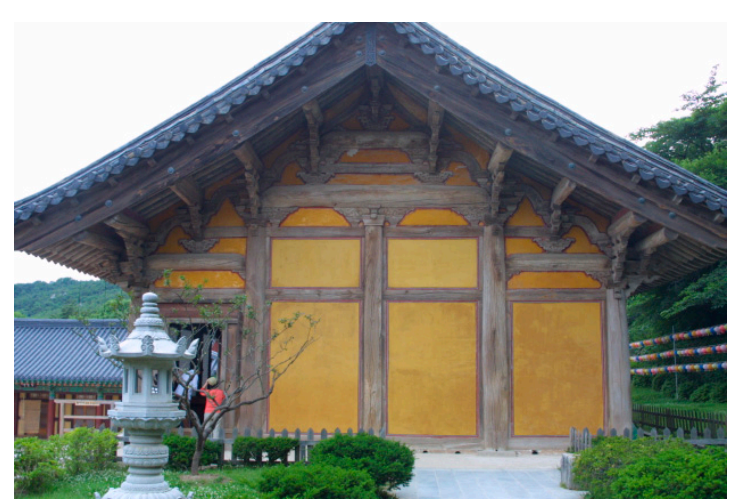

(a)

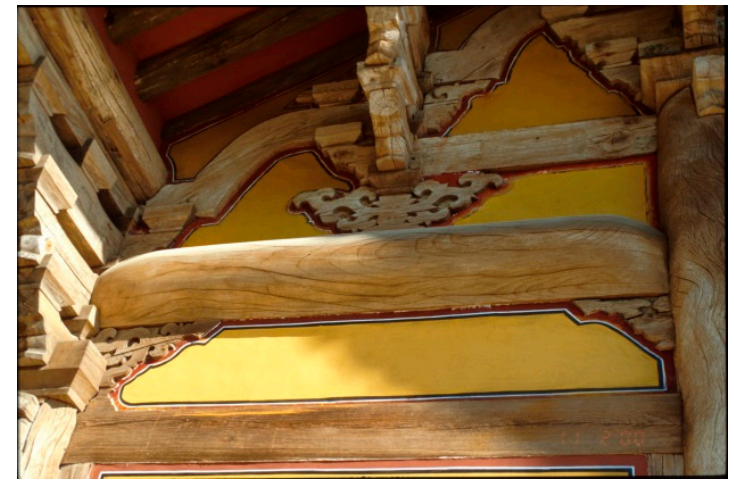

(b)

Figure 5. (a) Sudeoksa Daeungjeon elevation; (b) Sudeoksa Daeungjeon Umiryang (source: author).

Considering the previously mentioned features, it seems clear that the wooden architecture of the Goryeo Dynasty was endeavoring to create specific aesthetics from the elaborately processed curves in structural elements such as columns and girders. Furthermore, it was during the Goryeo Dynasty when great efforts were made to complete the formative beauty to the highest level through active cultural exchanges with neighboring countries similar to other art disciplines such as pottery and crafts.

\section{Joseon Dynasty (Approximately 1392-1910)}

\subsection{Early Joseon Dynasty (1392-1592): The Restrained and Weakened Curvature}

There are notable wooden buildings of the early Joseon Dynasty including Bongjeongsa Daeungjeon, Gaesimsa Daeungjeon, Muwisa Geukrakjeon, Gwanryongsa Yaksajeon, Songgwangsa Guksajeon, and Songgwangsa Hasadang and Sungryemun in Hanyang, which was the capital at the time. In addition, there are a number of wooden buildings of the early Joseon Dynasty still remaining in some culturally preserved villages.

Compared to the architecture of the Goryeo Dynasty, the curves in architectural components of the early Joseon period can be described by two trends: the weakening of the curvature and a curve close to a straight line.

For example, the Baeheulim pattern, one of the most representative features of the Goryeo era, became indistinct in the buildings of this period. It tended to be visually unapparent even if it was 
applied. However, there are many columns that gradually become narrower from the bottom to the top. This type of column is called a "Minheulim" column.

Additionally, Umiryang, which had been used in the Goryeo Dynasty, was also applied to the wooden architecture of the early Joseon Dynasty. With regard to temple architecture, Gwanryongsa Yaksajeon, Gaesimsa Daeungjeon, and Dogapsa Haetalmun are among the well-known Buddhist temples with Umiryangs installed in the early Joseon era. Except for the temple buildings, Jeonjugaeksa Jungchung, a government building in the city of Jeonju, shows how an Umiryang looked at the time. Compared with the Umiryang of the Goryeo Dynasty, the curvature of this Umiryang, in terms of the ratio of the width to the length of the curve, became less steep and weakened in the Joseon Dynasty (Figure 6).

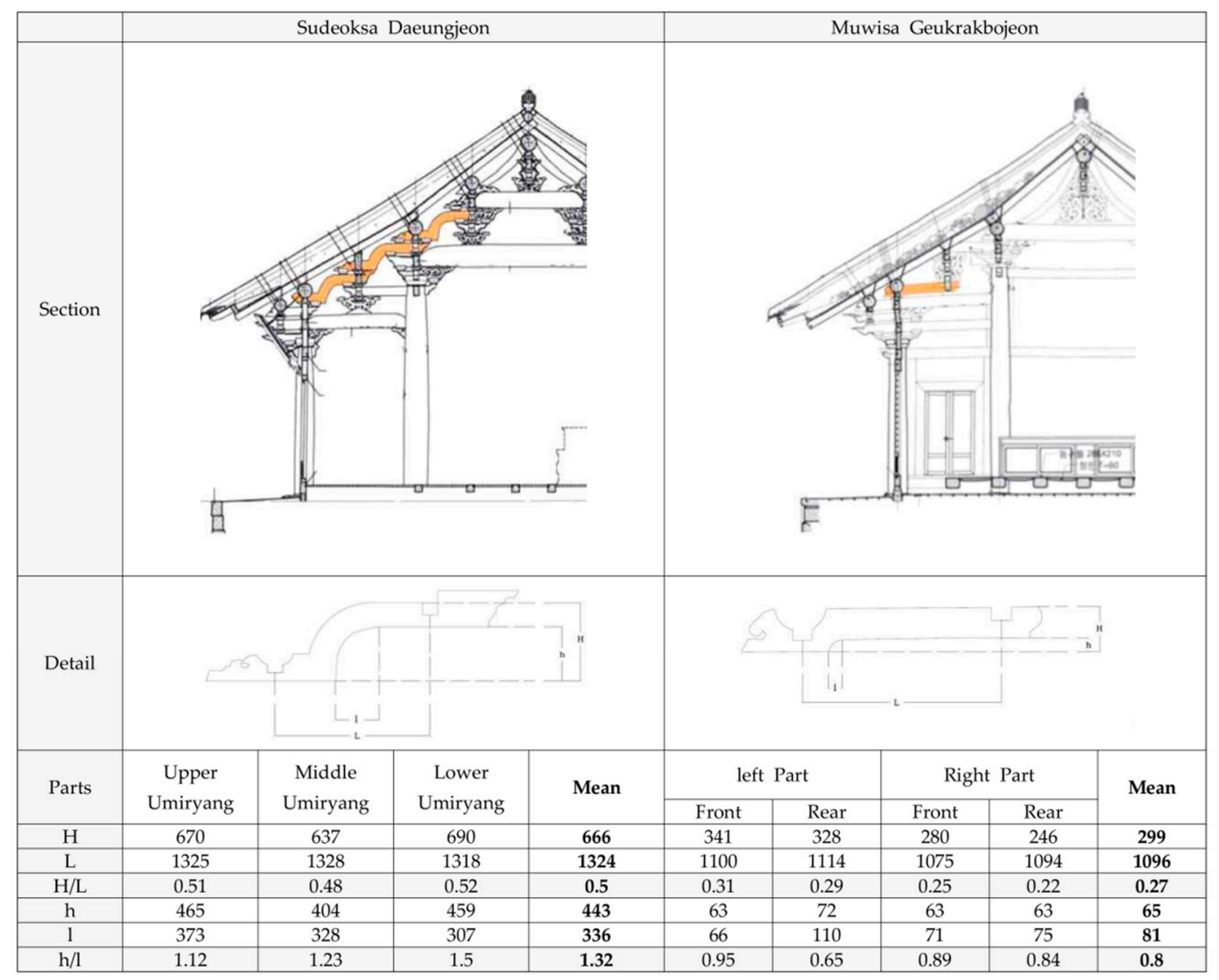

Figure 6. Height proportion $(\mathrm{H} / \mathrm{L})$ and curvature $(\mathrm{H} / \mathrm{L})$ comparison between Sudeoksa Daeungjeon (Goryeo Dynasty) and Muwisa Geukrakbojeon (Early Joseon Dynasty) (source: author's edit. Cultural Heritage Administration).

Comparing the section between Sudeoksa Daeungjeon of the Goryeo Dynasty and Muwisa Geukrakbojeon of the early Joseon Dynasty [14], there is a clear distinction of the curved wooden member, Umiryang. When it comes to the height proportion of the member, the height becomes much lower than the member length from Goryeo to the early Joseon. The proportion, H/L, can be seen from Figure 6: 0.5 to 0.27 . From the point of the curvature, both $\mathrm{h}$ and 1 are getting smaller. If both height distances were lowered equally, there would be no change in $\mathrm{H} / \mathrm{L}$. As a result, although the curved wooden member is still used from the Goryeo Dynasty to the early Joseon Dynasty, the deliberate formative curve of the Goryeo Dynasty is clearly reduced in the Confucian society of the Joseon Dynasty.

Muwisa Geukrakjeon has drawn attention for its architectural qualities of the time responding to the changes of the Umiryang. The crossbeams show different shapes from one another based on the 
columns' position supporting them, and Daedeulbo (a crossbeam or girder) of the largest diameter was installed in the center. However, Toetbo, a kind of thinner crossbeam, was used on the side of the building, and the Umiryang was placed on the top of the Toetbo. As the result, the combined height of the Toetbo and the Umiryang is equal to the Daedeulbo. Based on these changes, we can predict that future architectural works will use a Daedeulbo with a larger diameter, and the Umiryang will become obsolete.

The weakening of the curve is also because the size of the building was reduced and the number of components used to make the building decreased. As a result, the cost and effort invested in the building were reduced.

In addition, the kings and the leaders of the Joseon Dynasty suppressed Buddhism. It was impossible to officially become a monk, and the benefits of applying to temples disappeared. Therefore, it was impossible to build new buildings on a large scale, and it was not easy to repair and maintain existing buildings [2].

Compared to the time when Buddhism was suppressed, the Joseon Dynasty's national ideology was Neo-Confucianism, where leaders of Confucianism valued the practice of moderation and a frugal lifestyle. This idea was well reflected in the architecture. The representative buildings were their houses and other educational facilities such as Seowon. The curved building components, Daedeulbo and Chungryang, a perpendicular beam to the Daedeulbo, can also be seen in the houses and the Seowon building.

Daedeulbo is a very important component of East Asian wooden architecture that connects the front and rear columns, regardless of the size and type of building. Therefore, it is essential even in small-scale buildings and houses. The smallest and simplest structure, "3Ryang-jip", is basically two columns supporting a crossbeam, and a short column called Daegong is placed on the crossbeam holding a gable roof (Figure 7b). Several houses of the early Joseon Dynasty, such as Songcheomjongtaek, Gwangajeong, Hyangdan, and Muchumdang were built using very simple structures that have been well preserved, especially in Yangdong village [15,16].

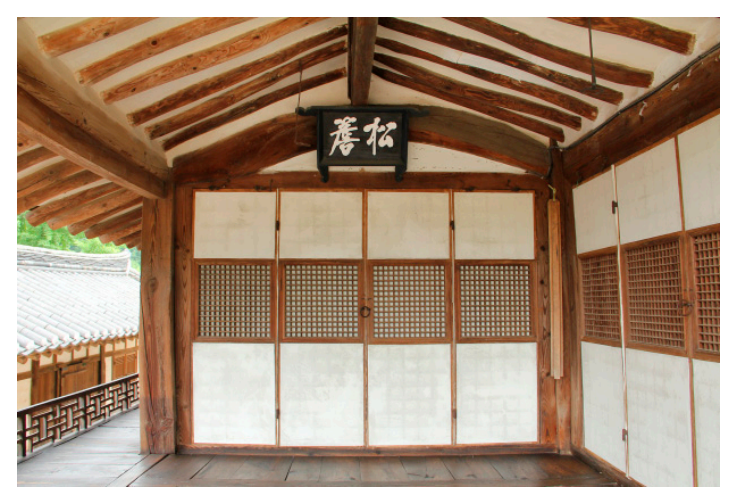

(a)

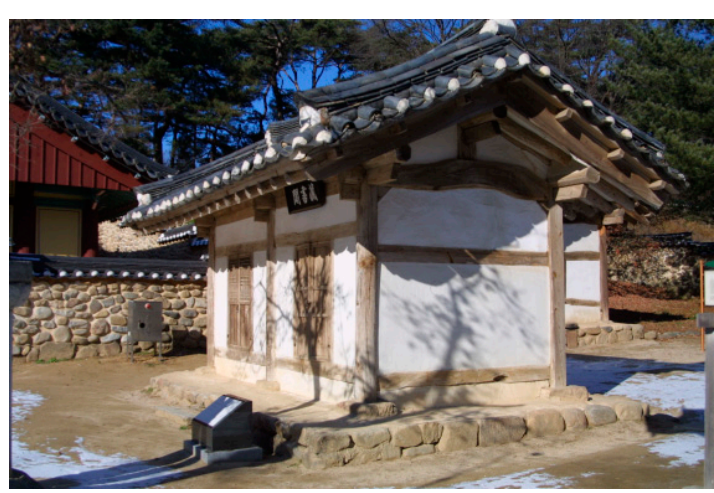

(b)

Figure 7. (a) Songcheomjongtaek's Sarangchae crossbeam; (b) 3Ryang-jip at SosuSeowon (source: author).

Since the distance between the front and rear columns is small and the building is not very tall, a convex-shaped timber is used for the girder (Figure 6 left). This structure makes the ceiling of the indoor space look high and reduces the cost of construction. In spite of the small size of the building, there is a feeling of openness. This kind of structure supports the guiding principles of Joseon Dynasty architecture: restrained simplicity while considering functionality.

There is a saying "Gumibulu" in Korean to describe this kind of aesthetic, which translates to "looking frugal but not shabby". Similar to Gumibulu, there is also "Hwaibulchi", meaning "looking splendid but not extravagant". 
Chungryang, the perpendicular beam to Daedeulbo, is a common component that is used in traditional Korean architecture to make "Palchakchibung", which is a type of half-hipped roof in the wooden buildings of Joseon. Chungryang is connected to the Daedeulbo at a right angle and is a unique structural feature of the Korean wooden architecture. Ojukheon [17] and Haeunjeong [18] in the city of Gangneung are among the representative cases installed with Chungryang in the early Joseon Dynasty. The length of a Chungryang is 1 Gan (about $3 \mathrm{~m}$ ), and the shape is close to a straight line. In particular, the edge of the beam connected with the main girder is a straight line. However, on the opposite side, the joint part connected to the column was processed into a curved shape. Except for residences, Chungryang is also found in Seowon, which is a private educational institution of the Joseon Dynasty. SosuSeowon [19] is the first Seowon in Korea, revealing that the layout of the building at that time was not yet formally set up. In the Seowon, there is a building called Ganghakdang (lecture room), which was built at the time [20]. Myongryundang has Palchakchibung, just like Ojukheon and Haeunjeong in Gangneung, and thus Chungryangs were installed at a right angle to the Daedeulbo (Figure 8). The Chungryang appears to be almost a straight line. From a profile view, the bottom part is shaped as a curved line toward the point connecting the columns, while the top part of the Chungryang looks like a straight line.

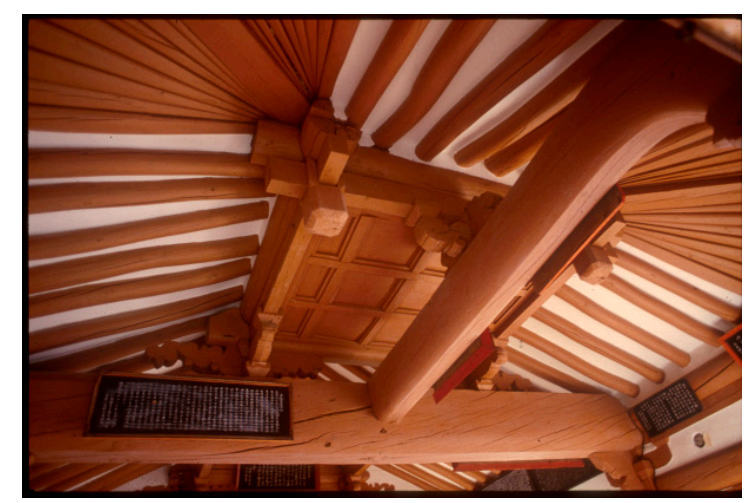

(a)

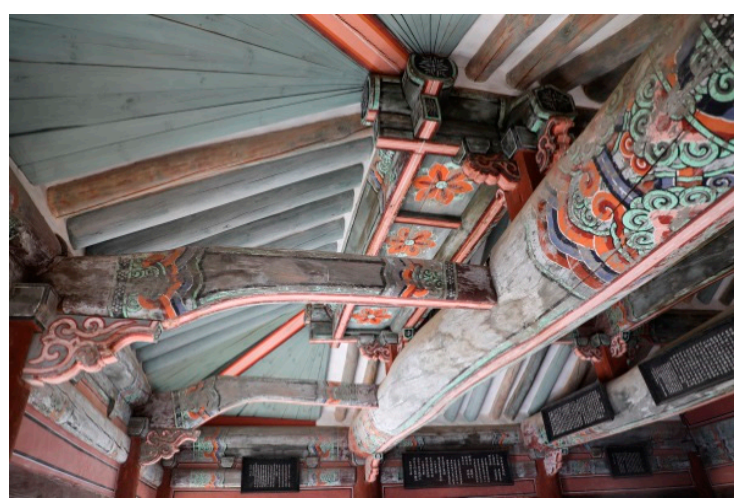

(b)

Figure 8. (a) Gangneung Ojukheon "Chungryang"; (b) SosuSeowon Ganghakdang (lecture hall) "Chungryang" (source: author).

Among the representative buildings of the Joseon Dynasty, the philosophy and ideas of Neo-Confucian scholars are well reflected. As such, there are historians who contend that the role of architects in the Joseon Dynasty can be seen as Confucian scholars [21]. A notable example of this argument is from Lee Hwang of the early Joseon Dynasty, who built Dosan Seodang, which reflects his taste for a frugal lifestyle suitable for a scholar [22].

\subsection{Mid-Joseon Dynasty (1592-1800): Application of Naturally Curved Timber}

Between the end of the 16th century and the first half of the 17th century, massive international wars took place during the Joseon Dynasty. Hence, Joseon found itself in its worst situation economically and socially. Two wars, Imjinwaeran, the Japanese Invasion between 1592 and 1598, and Byongjahoran, the Manchu war from 1636 to 1637, were among the most well-known ones. The complex social circumstances including a reduced population, restoration from the destruction of the wars, and challenging foreign relations were reflected in the architecture as well. Nevertheless, there were some positive aspects of these difficulties. In the process of overcoming the physical and mental damage, Korean society gained a new perspective, adopting more rational and pragmatic thinking and rejecting old customs, and this social trend was also reflected in architecture. While the nation's power had been weakened by the war, on the contrary, Korea's unique techniques had been developed and incorporated in the formative arts and architecture [23]. 
For example, the Toetbo beam was a widely used component of Korean housing construction because of its many advantages. Among them, a special case can be found in Dorae village in the city of Naju, which is one of the representative historic villages of the mid-Joseon Dynasty. The oldest building in the village is Unamgotaek Sarangchae, which was constructed in 1732 [24]. This building has a unique feature in the layout of the columns. In general, columns of a wooden building are placed, aligning lines from the front and rear as well as the left and right. However, in the Unamgotaek Sarangchae, the columns are not arranged on an orthogonal grid if comparing right and left columns. From the right, two columns do not match the one on the front and the other on the side.

To create such a plan, a different structure needed to be applied. Generally, a crossbeam connects two columns directly. However, if the row of the columns is not aligned in a straight line, it is impossible to install a horizontal beam between the columns. Therefore, one side was connected to the column, and the other side where there was no column was connected to a purlin at a higher level. Due to the level difference, the crossbeam had to be bent, and thus was made of naturally curved timber (Figure 9a).

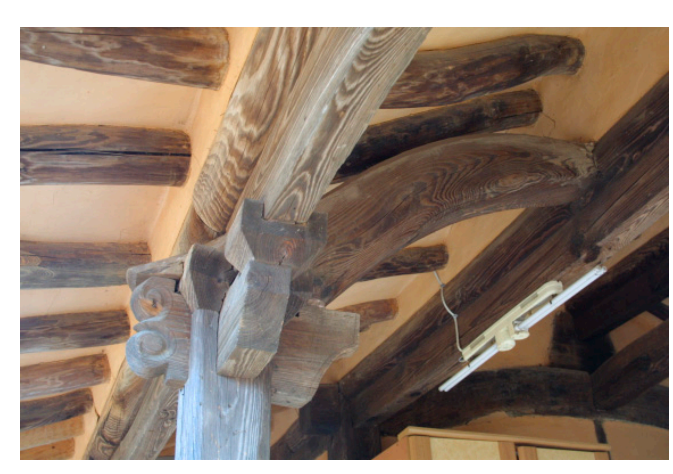

(a)

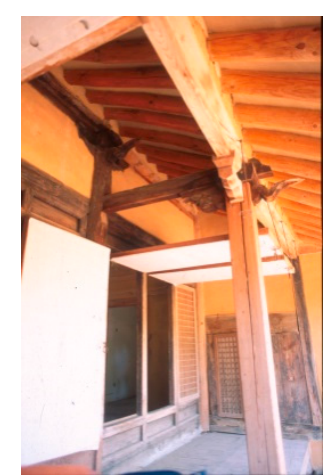

(b)

Figure 9. (a) Toetbo Beam at Unamgotaek Sarangchae in mid-Joseon; (b) Toetbo Beam at Mangcihangdan in early Joseon (source: author).

It is possible to speculate why the conventional column arrangement was not used in that period. First, a visual effect can be created where the floor would look larger if viewing the building from the front. At present, the front of the Daechung appears to be two bays long. If the column had been positioned normally, the front of the Daechung would be appeared to be 1.5 bays. Actually, the front bay of the Daechung was seen as a symbol of the social status of the homeowner in Korea. Homeowners generally thought three bays were the ideal modules for the Daechung in order to show the dignity of the house.

Second, this arrangement helps enlarge the vertical indoor space. If the columns are aligned in a straight row, there needs to be a horizontally straight crossbeam to connect them, and its level would be lower than the current convex one. As a result, it would be impossible or uncomfortable for a person to stand and pass under the beam. In addition, a regular alignment of the columns lines would result in a smaller area from the edges of the Daechung, leading to a poor use of space.

The current plan of Unamgotaek resulted from considering the size of the elevation view of the floor and the use of space. This type of plan was enabled by the use of naturally curved timber. Carpenters at that time strove to find such timbers in nature.

The extended Toetbo beam was also used for shade. On the opposite side, to the east of Korea, and east of Naju in Jeonlanamdo, there is a city called Yeongcheon in Gyongsangbukdo where the Sunwondong village is located. In that village, there is a housing site called Yeonjunggotaek that has been listed as a nationally designated cultural asset [25]. It is composed of a main house and a pavilion. In this paper, the Yeonjung pavilion is discussed in terms of the use of curved timbers, since the ideas applied to maximize the building's function are very unique. 
The original structure of Yeonjung was a simple "3Ryang-jip" style. The roof was composed only of rafters, creating short eaves. If the eaves are short, the structure is vulnerable to rainfall as well as wind or strong sunlight. Therefore, the rafters of Yeonjung were extended with a Buyeon. If the building had followed the original plan, it could have been installed without another column. However, because it was enlarged, the columns had to be built up outside in order to hang the Buyeon as an extension of the roof. Since there was a height difference between the existing and new columns, a bent connecting beam had to be used. In this way, the roof provided proper protection against rainstorms and sunlight as an awning. Therefore, naturally curved timbers became a very useful building material sought after by carpenters (Figure 10).

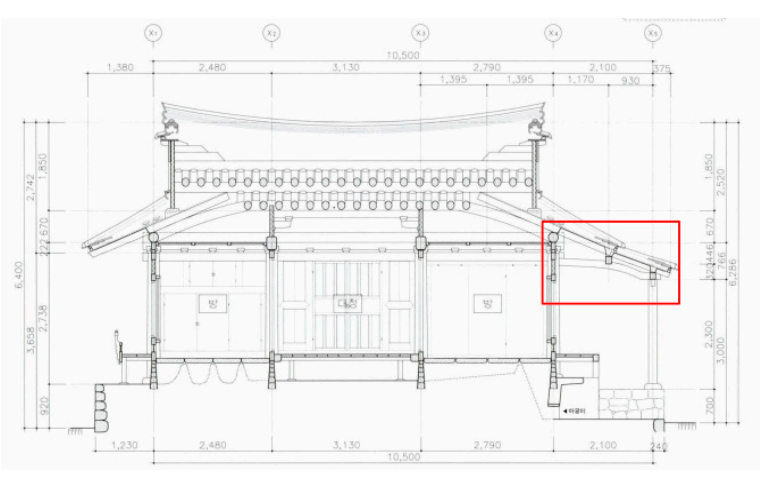

(a)

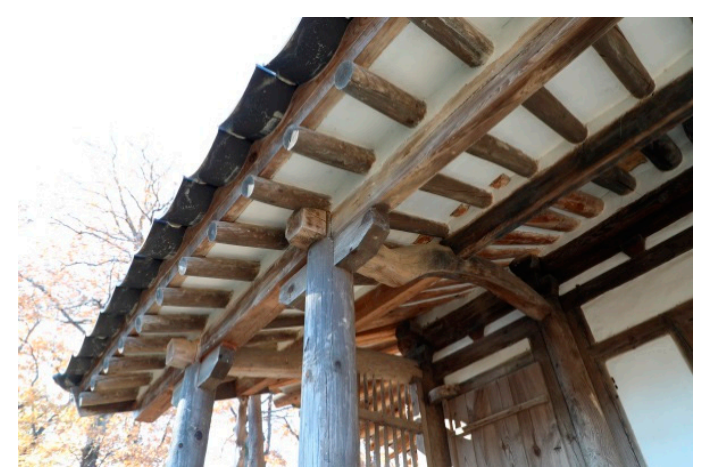

(b)

Figure 10. (a) Yeonjung Pavilion Section (source: author's edit. Cultural Heritage Administration); (b) Yeonjung Pavilion Toetbo Beam (source: author).

There are some distinctive features when comparing the wooden buildings in historic villages between the early and mid-Joseon eras. Those in mid-Joseon used curved timbers in more diverse positions, while the curved timbers in early Joseon were not frequently used for girders.

In Unamgotaek Sarangchae, curved timbers were applied to columns and purlins. The use of curved timber enlarged the front view and heightened the indoor space. In Yeonjunggotaek's pavilion, curved timbers were used to extend the eaves and to create a unique awning. All these practical solutions resulted from the carpenters' ideas, which corresponded with the philosophy and attitude of "Gyongsaechiyong" in Silhak (the Realist School of Confucianism). The incorporation of Silhak ideas in architecture can be seen when Jeong Yakyong built a new city called Hwasung with the support of King Jeong-Jo at the end of the 18th century. However, the signs that practical ideas would be reflected in architecture were already appearing in the mid-17th century. Yoo Hyongwon, one of the pioneering Silhak scholars, argued in his book Bangyesurok that it was time to change the functions of traditional cities [3].

\subsection{Late Joseon Dynasty (1800-1910): Symbolic and Creative Use of Naturally Curved Timber}

In the late Joseon period, a representative characteristic is the increased use of decorations in the building, especially featuring dragons. In the architectural style called Dapo, a building component called Anchogong is constructed on the top of the building columns. It originally looked very simple in the palace building where Anchogong was used for the first time. It was the Daeungjeon of the Yosu Heungguksa built in 1690 that started to engrave the dragon in Anchogong [26]. Another example is Yosu Jinnamgwan built in 1718, which was an army training facility. Interestingly, both are located in Yosu, which is a harbor city. Thus, the navy was stationed there and had a military unit consisting of Buddhist monks at that time. The Anchogongs in the palace buildings did not have sculpted dragon features. The Anchogongs with engraved dragons were found only in the temple buildings, except for those in Jinnamgwan (Figure 11a). 


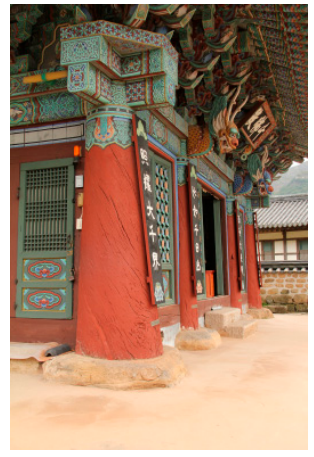

(a)

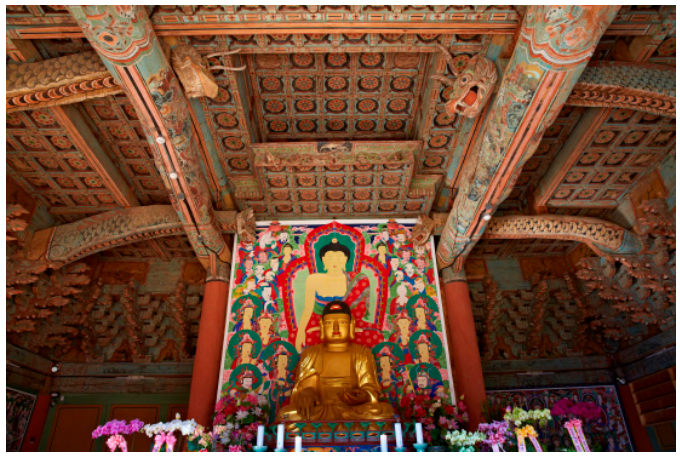

(b)

Figure 11. (a) Exterior dragon-carved Anchogongs at Daeheungsa Chunbuljeon (source: author); (b) Interior dragon-carved Chungryangs at Seonamsa Daeungjeon (source: Sansa World Heritage Registrations Promotion Committee).

A dragon sculpture of the Anchogong seen in the front of the temple building has made the Buddhist temple itself a Banyayongsun, meaning a dragon-propelled boat to Geukrakjeongto, the Buddhist paradise. There was a notion that regarded the temple building as the boat to paradise, which influenced the dragon decoration on the top of the columns [27]. There are also some temples whose murals included paintings of dragon boats (Figure 12).

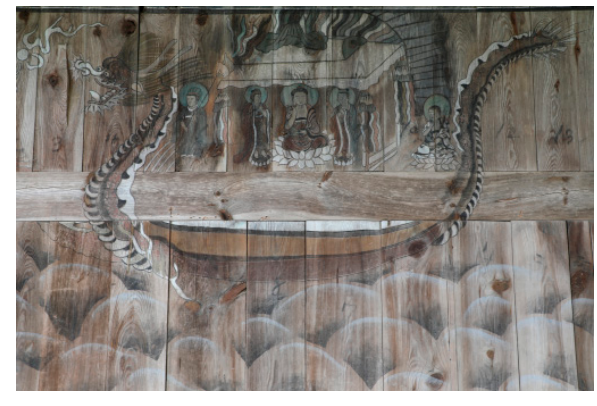

(a)

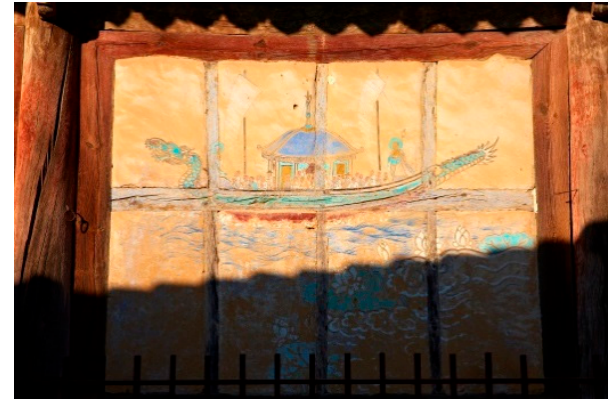

(b)

Figure 12. (a) Painting of Banyayongsun (Bogwangsa Daeungjeon); (b) Painting of Banyayongsun (Tongdosa Geukrakjeon) (source: author).

As previously mentioned, Chungryang is one of the architectural structural elements used since the early Joseon Dynasty. However, inside the main building of the Buddhist temple, the ornament of the dragon sculpture began to be used as an Anchogong of the pillar. It is in the same position and functions as the Chungryang from the early Joseon houses or Seowon buildings. However, although there was no decoration and it was created to be straight in the early Joseon period, the head of a Chungryang in the late Joseon was sculpted with a dragon head. Dragon sculptures that appeared in the late 17th and early 18th centuries were also used indoors.

The first place where Chungryangs carved with dragons were used was Yosu Jinnamgwan [28]. Since then, Chungryangs decorated with dragon sculptures were widely used in Buddhist temples [29]. The first temple was Hwasung Yongjusa Daeungbojeon where dragon sculptures were used in only two of the four Chungryangs located at the front. In large buildings, four Chungryangs were usually used in the front, rear, left, and right. In the temple of Seonamsa built in 1824, four dragons are positioned onto four Chungryangs (Figure 11b).

The Chungryang in the late Joseon Dynasty tended to use bent timber as its natural shape, compared to the Chungryang of the early Joseon era. As discussed above, the Chungryang of the early Joseon dynasty was constructed in a relatively straight line. In addition, the Chungryang of this time 
was relatively thinner, and the head of the Chungryang did not protrude from the Daedeulbo, the girder. The Chungryangs in the late Joseon Dynasty used natural timber almost without processing, which was suitable to express the dynamic shape of a wiggling dragon. Additionally, dragon scales were painted on the body of Chungryang.

The following conclusions can be drawn by synthesizing what was discussed earlier. First, the dragon decorations in the building are likely to have been started by Buddhist monks. Second, the dragon decorations used in government offices or main buildings of palaces were symbols of authority, but the dragon decorations in the temple's main building have come to represent a concrete image of a dragon-drawn ship.

In addition to the temple buildings, there is another example of the symbolism of the architecture in the late Joseon era. Milyang Yongnamru built in 1844 was one of the large pavilions belonging to a local government accommodation facility, a Gaeksa. The Gaeksa housed Jeonpae, a tablet with the word Jŏn, which was kept as an emblem of the king's presence, and people pledged allegiance to the king. This building was also used as a guest house for government officials who visited from the central government in Seoul. Therefore, Yongnamru, the pavilion belonging to the guest house, was mainly used as a recreational spot for the officials to enjoy the surrounding scenery and to relax while writing poetry.

Yongnamru is composed of three buildings. There is the main building in the center, Neungpagak at a higher place on the left, and Chimryugak at a lower place on the right. The word "Chimryu" in Chimryugak is the abbreviation of Suseokchimryu, which is a metaphorical expression meaning "soothing the weary body and mind in nature". In addition, the literal meaning of Chimryu is "a pillow on the water" or "to use water as a pillow". If a person lies down on the Chimryugak, there must be water below the person's head as a metaphor. In addition, the water in the main building at the higher location needs to flow down to Chimryugak. In order to complete this metaphoric image of falling water, a staircase-shaped corridor was built between the two buildings [30]. Naturally curved timber was used to create the staircase-shaped building. This wood was also used for the stairs. The architect of Yongnamru in 1844 intended to show the meaning of Chimryu by means of shaping the building as a cascade of stairs (Figure 13).

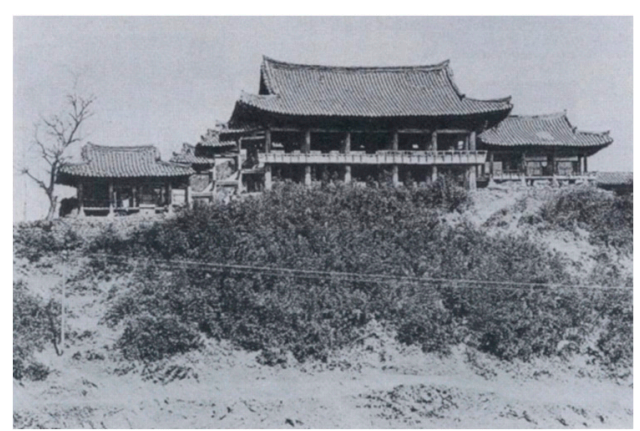

(a)

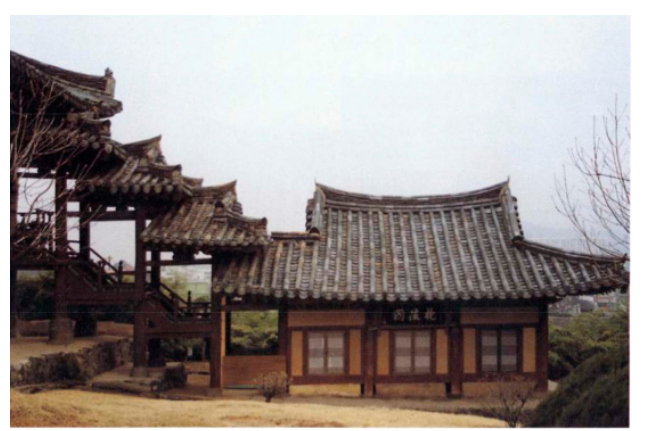

(b)

Figure 13. (a) View of Milyang Yongnamru from South; (b) Staircase-shaped corridor in Chimryugak of Milyang Yongnamru (source: Cultural Heritage Administration [31]).

As a result of examining the buildings built in the late Joseon Dynasty, the tendency to use curved timbers is clear. First, in temple architecture, curved timbers were used for Chungryangs. It was the same Chungryang as used in other times, but they were thinner and in a relatively straight form in the early Joseon buildings. However, in the late Joseon dynasty, the naturally curved timbers for Chungryang were used to express wiggling dragons in the temple architecture. The dragon symbolized a strong presence in charge of defending people accompanied by Buddha, a leading figure to defeat bad energy. The dragon sculptures originated from the exterior of buildings, but later the use increased, 
eventually expanding into the interior as well. The temple building decorated with the dragon figures represented Banyayongsun, the dragon boat to paradise.

In addition, curved timbers in a government building were used to create a staircase building. In order to connect the upper and lower levels of buildings, a staircase was placed in the middle, symbolizing the gathering of water falling from a high place to a low place. Moreover, the structure symbolizes Chimryu, a person lying down and resting on water. In the late Joseon period, the bent wooden structure is expanded to give meaning beyond the function compared with the functional use of the bent wood. In contrast to the architecture in the mid-Joseon period when the curved timbers were used just functionally, the use of those in the late Joseon era gave symbolic and metaphoric meanings to the buildings.

\section{The Characteristics of Curved Wooden Members in the Early, Middle, and Late Joseon Dynasty}

Seeing the representative architecture of each period of the Joseon Dynasty, the height proportion and curvature of the curved wooden members show their expressional characteristics related with social background (Table 1, Figure 14). In terms of the height proportion $(\mathrm{H} / \mathrm{L})$, the length of the members becomes longer in the middle $(3057 \mathrm{~mm}$ ) and late $(3606 \mathrm{~mm})$ Joseon periods compared to the early Joseon period $(2222 \mathrm{~mm})$. Since the curved woods are structural members, the lengthening of the members means that the functionality also becomes stronger over time. On the other hand, the height of the members increased from the early Joseon $(435 \mathrm{~mm})$ to the mid-Joseon $(929 \mathrm{~mm})$.

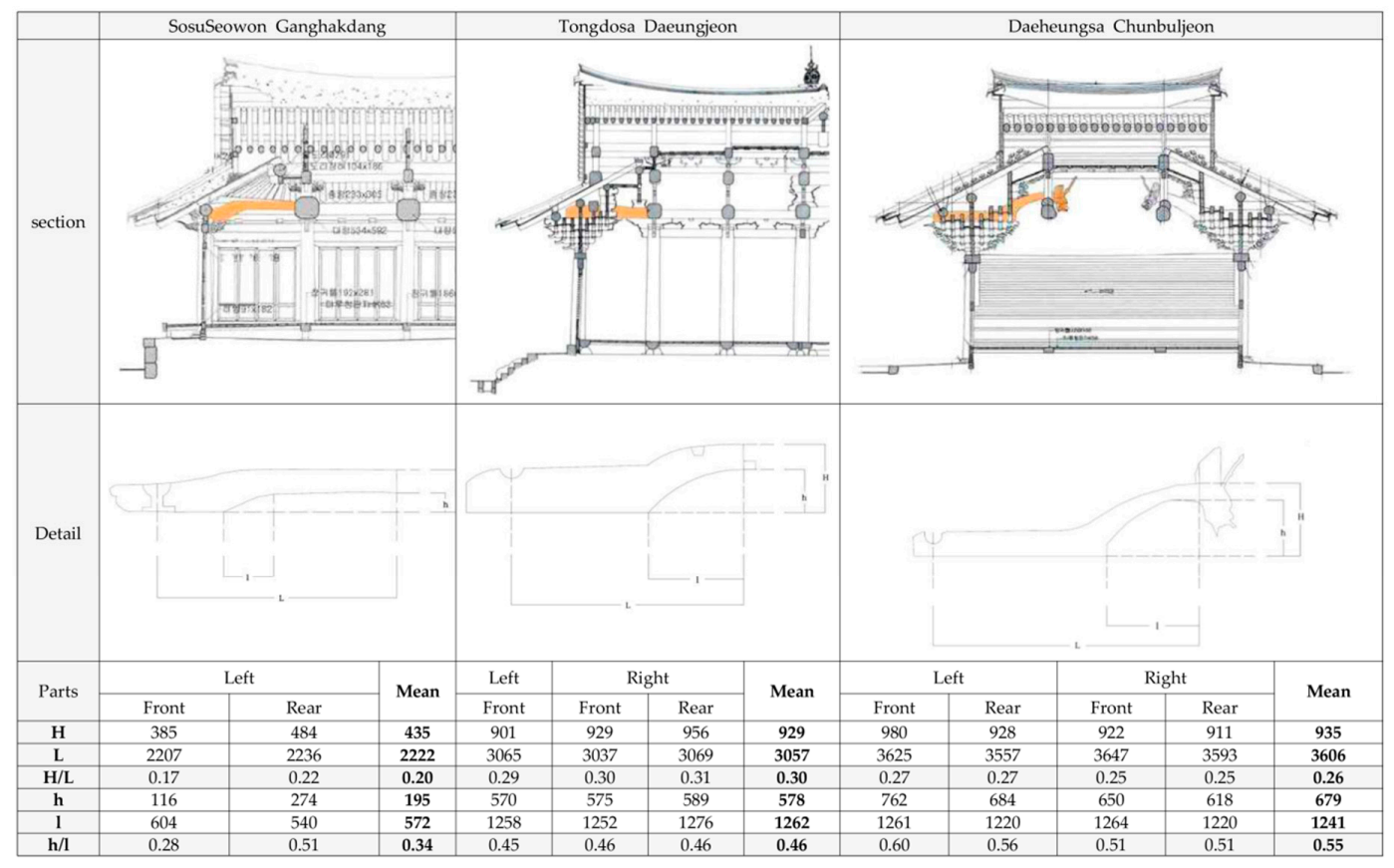

Figure 14. Height proportion (H/L) and curvature (H/L) comparison among SosuSeowon Ganghakdang (Early Joseon), Tongdosa Daeungjeon (Mid-Joseon), and Daeheungsa Chunbuljeon (Late Joseon) (source: author's edit. Cultural Heritage Administration).

This indicates that Confucianism's strict norm of the early Joseon period weakened in the mid-Joseon period. In other words, the dramatic height change using curves disappeared in the culture, emphasizing the moderation of the early Joseon period, after which it reappeared in the mid-Joseon period. As a result, the distinctive difference in $\mathrm{H} / \mathrm{L}$ is found between the early and the middle of Joseon periods, while the middle and late Joseon periods remain unchanged. Since the middle and late Joseon used naturally curved wood, the materials have a limitation, which that they are hard to fabricate. 
Table 1. Periods of Joseon Dynasty and its Architecture, Expression, and Social Influence

\begin{tabular}{|c|c|c|c|}
\hline Period of Joseon & Early & Middle & Late \\
\hline Architecture & $\begin{array}{l}\text { SosuSeowon } \\
\text { Ganghakdang }\end{array}$ & Tongdosa Daeungjeon & $\begin{array}{l}\text { Daeheungsa } \\
\text { Chunbuljeon }\end{array}$ \\
\hline $\begin{array}{l}\text { Type of Curved Wood } \\
\text { Expression }\end{array}$ & $\begin{array}{l}\text { Processed Curve } \\
\text { Asceticism }\end{array}$ & $\begin{array}{c}\text { Naturally Curved } \\
\text { Pragmatism }\end{array}$ & $\begin{array}{l}\text { Naturally Curved } \\
\text { Symbolism }\end{array}$ \\
\hline Social Influence & Neo-Confucianism & $\begin{array}{l}\text { Wars and Silhak (the Realist } \\
\text { School of Confucianism) }\end{array}$ & Elegant Culture \\
\hline
\end{tabular}

When it comes to the curvature $(\mathrm{H} / \mathrm{L})$, height is getting higher as time passes, and there is a remarkable difference in length between the early Joseon $(572 \mathrm{~mm}$ ) and the mid-Joseon Dynasty (1262 mm). In addition, $\mathrm{H} / \mathrm{L}$, the curvature, increases from the early to the late Joseon period. In the Confucianism society of the early Joseon period, the curvature was weakened, but the formal identity was maintained. Furthermore, it was actively used again in the mid-Joseon period related with social changes, wars, and Silhak. In the late Joseon period, the size and curvature of materials did not change much compared to the mid-Joseon period, but it contained semantic symbolism.

\section{Conclusions}

Curved timbers were used to show the partial as well as the total formative aesthetics of buildings in the Goryeo Dynasty (10-14 C). Thus, the shape of the curve was thoroughly calculated and carefully designed. The Baeheulim-style column, Umiryang, and the cross-sections of the beam are among the representative examples in that period.

On the other hand, in the early Joseon Dynasty (15-16 C), a simple curve was used compared to the Goryeo period. Specifically, the wood was processed in a shape close to a straight line, and a curved shape was applied only if necessary. Another style involved using bent timbers taken from nature, which preserved the naturally curved shape selectively in the housing buildings. This is a sustainable formal alteration of curved wooden members, because the change makes it possible for people of the era to effectively save construction time and cost. The practical idea comes from the dominant social paradigm, Neo-Confucianism, which emphasized the austerity of life.

In the mid-Joseon Dynasty (17-18 C), curved timbers were used creatively by architects or carpenters to serve practical functions. In order to maintain the function of the buildings most effectively, they used the naturally curved wooden members. The application of the wild timbers minimized the manufacturing process and maximized the pragmatic functionality of the space under the influence of severe wars and Silhak (the Realist School of Confucianism).

In late Joseon Dynasty's (19-20 C) wooden architecture, the architects or carpenters gave symbolic and metaphoric meanings to the buildings beyond practical solutions by using the curved timbers.

The different characteristics of the use of the curved wood are closely related to the political and economic situation. For example, since the Goryeo Dynasty was a Buddhist state, the buildings built in the temples were the best masterpieces of the time. However, in the Joseon Dynasty, large-scale constructions were reduced except for the palace buildings, and the Confucian architecture built in the province was more praised for its frugal appearance. The international wars of the late 16th and early 17th centuries had devastated the country, resulting in the shortage of trees suitable for building, and people increasingly focused on building a practical way. After the renaissance of King Yengjo and King Jeongjo in the 18th century, national power was restored, and in the 19th century, there were many changes in architecture, which led to a large number of decorations and attached a lot of meanings to the forms. After all, even though the political, economic, and cultural situation changes according to the times, it can be seen from the curved woods that 'natural friendly' traditions continue unbroken in Korean traditional architecture.

The curved form in the stair shape of the Goryeo Dynasty and the corridor of Milyang Yongnamru in the late Joseon Dynasty has a similar resemblance (Figure 15). The curved structures of Sudeoksa 
Daeungjeon are intended to look aesthetically pleasing, and the curved stairs of Yongnamru were designed to mimic the image of a waterfall. The two different buildings show the tradition of Korean architecture that has been passed down for nearly a thousand years.

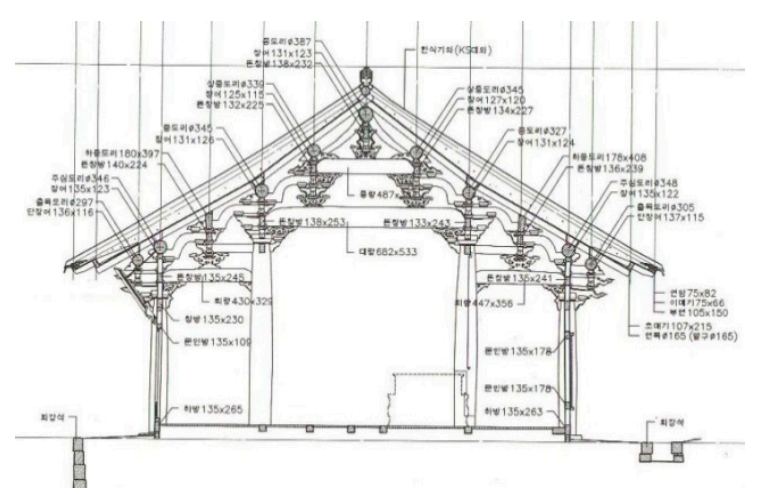

(a)

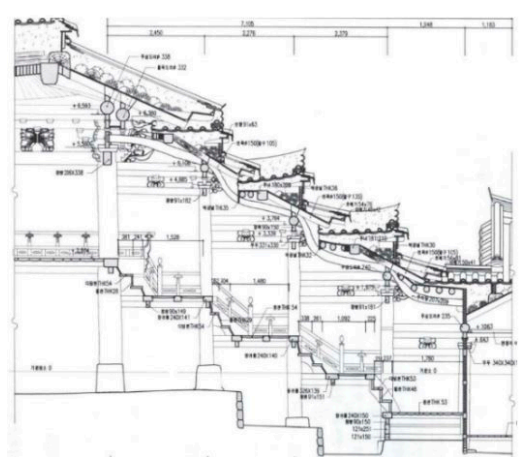

(b)

Figure 15. (a) Building with curved timber in the Goryeo Dynasty (918-1392); (b) Building with curved timber in the Late Joseon Dynasty (1800-1910) (source: Cultural Heritage Administration).

To sum up, examining historical alteration of the parts and shapes of the curved wooden members, it is possible to identify the sustainable aspects of Korean traditional architecture and to infer the influence of the historical background on forming the sustainability of the architecture. While the Goryeo Dynasty (10-14 C) had an aesthetic climax of the extravagant curved structures precisely designed under the backgrounds of Buddhism and aristocracy, the early Joseon Dynasty (15-16 C) showed restrained curved shapes of wood details with fewer materials and a faster building process due to Neo-Confucianism, which emphasized austerity. After tremendous social crisis, including two wars, the mid-Joseon Dynasty (17-18 C) showed very creative indigenous houses with naturally curved timbers minimizing the manufacturing process and maximizing the pragmatic functionality of the space under the influence of the wars and Silhak (the Realist School of Confucianism). In addition, the late Joseon Dynasty (19-20 C) presented office buildings with strengthened dynamic shapes of the naturally curved timbers as symbolic expression, which is an expanded concept beyond the functionality. In Korean traditional architecture, curved wood members have been used without interruption, although in varying degrees depending on social and economic situations, and have continued to be one of the characteristics of Korean architecture. Thus, the study of the curved wooden members of historical heritage architecture of South Korea is a good opportunity to understand the sustainability of the traditional buildings themselves, as well as the cultural and historical background. In addition, the application of the curved wooden members needs to be studied in terms of biophilic design today, because of their biomorphic forms and material connection with nature [32].

Author Contributions: All authors contributed substantially to this study. Individual contributions are: conceptualization, S.L.R.; methodology, S.L.R.; validation, S.L.R. and H.C.Y.; formal analysis, S.L.R.; investigation, S.L.R. and H.C.Y.; resources, S.L.R. and H.C.Y.; data curation, S.L.R.; original draft preparation, S.L.R.; review and editing, H.C.Y.; visualization, H.C.Y.

Funding: This research was supported by New Staff Settlement Research Fund (K1706171) funded by the College of Engineering, Korea University.

Conflicts of Interest: The authors declare no conflict of interest.

\section{References}

1. Mario, B. Oreiental Architecture 2; Electa/Rizzoli: Milan, Italy, 1981; p. 142.

2. Joo, N.-C. History of Korean Architecture; Korea University Press: Seoul, Korea, 2006; pp. 19, 351.

3. Kim, D. History of Korean Architecture; Gimundang: Seoul, Korea, 2007; pp. 21-24, $296-297$. 
4. Kang, G.-S. Korean Ceramics History; Yekyeong: Seoul, Korea, 2012; pp. 317, 541.

5. Cultural Heritage Administration. Report on Repair and Survey of Bongjeongsa Geukrakjeon; Cultural Heritage Administration: Daejun, Korea, 2003.

6. Lim, J.; Ryoo, S.L. K-Architecture: Tradition Meets Modernity; KOCIS: Seoul, Korea, 2013; p. 61.

7. Cultural Heritage Administration. Report on Survey of Sudeoksa Daeunjeon; Cultural Heritage Administration: Daejun, Korea, 2005.

8. Cultural Heritage Administration. Report on Survey and Repair of Gangneung Gaeksamun; Cultural Heritage Administration: Daejun, Korea, 2004.

9. Kim, D. Korean Wooden Architecture Techniques; Baleon: Seoul, Korea, 1993; p. 206.

10. Jang, G. Korean Wooden Structure; Boseonggak: Seoul, Korea, 1998; p. 133.

11. Liang, S. Yingzao Fashi Zhushi; China Architecture Industry Press: Beijing, China, 1983.

12. Wang, C.J.; Cha, J.; Yi, M.; Song, S.Y. Illustration of Classical Chinese Architecuture; Korea Publishing Co.: Seoul, Korea, 2016; p. 86.

13. Lee, Y. The relationship between china's Julgang province and Goryeo period's wood architecture through the beam connection-mainly on 'ChaKyon' and Chobang, 'Myoryang' and Umiryang. Kunchukyoksayongu 2016, 15, 75-86.

14. Cultural Heritage Administration. Report on Survey of Muwisa Geukrakjeon; Cultural Heritage Administration: Daejun, Korea, 2004.

15. Cultural Heritage Administration. Korean Traditional House 32: Yangdong Historic Village; Cultural Heritage Administration: Daejun, Korea, 2009.

16. Lee, S. Yangdong, Korean Historic Village; Cultural Heritage Administration: Daejun, Korea, 2008.

17. Cultural Heritage Administration. Report on Survey of Gangneung Ojukheon; Cultural Heritage Administration: Daejun, Korea, 2000.

18. Cultural Heritage Administration. Report on Survey of Gangneung Haeunjeong; Cultural Heritage Administration: Daejun, Korea, 1999.

19. Lee, S. Seowon: The Architecture of Korea's Private Academies; Hollym: Seoul, Korea, 2005.

20. Cultural Heritage Administration. Report on Survey of Ganghaktang and Munsunggomyo at SosuSeowon; Cultural Heritage Administration: Daejun, Korea, 2003.

21. Ben, J.; Robert, K. Korean Architecture: Breathing with Nature; Seoul Selection: Seoul, Korea, 2012; p. 67.

22. Kim, D. An Understanding of Joseon Dynasty Architecture; Seoul National University Press: Seoul, Korea, 1999; pp. 134-140.

23. Yoon, J.S. Korean Architecture; Seoul National University Press: Seoul, Korea, 1996; p. 374.

24. Cultural Heritage Administration. Korean Traditional House 37; Cultural Heritage Administration: Daejun, Korea, 2011.

25. Cultural Heritage Administration. Korean Traditional House 41; Cultural Heritage Administration: Daejun, Korea, 2013.

26. Cultural Heritage Administration. Report on Survey of Yosu Heungguksa Daeungjeon; Cultural Heritage Administration: Daejun, Korea, 2013.

27. Hŏ, G. Decorations of Buddhist Temple, the World of Its Shining Symbols; Dolbaege: Seoul, Korea, 2000; p. 23.

28. Cultural Heritage Administration. Report on Survey of Yosu Jinnamgwan; Cultural Heritage Administration: Daejun, Korea, 2001.

29. Hŏ, G. The Secrets of Korean Traditional Architecture Decorations; Boseonggak: Seoul, Korea, 2013; p. 128.

30. Ryoo, S.L. A Study on the Changes of the Government Pavilion, Miryang Yeongnamnu in terms of Function and Spatiality. J. Arch. Inst. Korea: Plan. Des. 2018, 34, 69-76.

31. Cultural Heritage Administration. Report on Survey of Miryang Yongnamnu; Cultural Heritage Administration: Daejun, Korea, 2000.

32. Park, S.J.; Lee, H.C. Spatial Design of Childcare Facilities Based on Biophilic Design Patterns. Sustainability 2019, 11, 2851. [CrossRef]

(C) 2019 by the authors. Licensee MDPI, Basel, Switzerland. This article is an open access article distributed under the terms and conditions of the Creative Commons Attribution (CC BY) license (http://creativecommons.org/licenses/by/4.0/). 